\title{
progresso técnico e subdesenvolvimento: uma síntese das abordagens de raúl prebisch, ragnar nurkse e celso furtado nos anos $50^{*}$
}

\author{
Renata D'Arbo \\ Universidade Estadual Paulista (UNESP), Instituto Municipal de Ensino Superior de Bebedouro \\ (IMESB). renatadarbo@mdbrasil.com.br
}

\begin{abstract}
RESUMO
O objetivo deste texto é resgatar as idéias predominantes nas análises de Raúl Prebisch, Ragnar Nurkse e Celso Furtado, no início dos anos 50, a respeito da relação entre progresso técnico e subdesenvolvimento. A intenção não é explorar todos os aspectos das contribuições de Prebisch e de Nurkse para o tema, é apenas identificar, nas reflexões destes dois importantes autores, contemporâneos de Furtado, indícios de que algumas de suas idéias poderiam ser contrapostas e/ou complementadas pelas idéias de Prebisch e de Nurkse. Este resgate contribui para uma visão retrospectiva da evolução das idéias de Furtado sobre a relação entre progresso técnico e subdesenvolvimento.
\end{abstract}

Palavras-chave: Progresso técnico, subdesenvolvimento, Raúl Prebisch, Ragnar Nurkse, Celso Furtado.

\begin{abstract}
The objective of this text is to retrieve the predominant ideas in the analysis of Raúl Prebisch, Ragnar Nurkse and Celso Furtado, in the beginning of the 50's, concerning the relation between technical progress and underdevelopment. The intention is not to explore all the aspects of Prebisch's and Nurkse's contributions to the theme. The intention is only to identify in the reflections of these two important authors contemporaries of Furtado, signs that some of his ideas could be contraposed and/or complemented by Prebisch's and Nurkse's ideas. This retrieval contributes to a retrospective view of the evolution of Furtado's ideas about the relation between technical progress and underdevelopment.
\end{abstract}

Key words: Technical progress, underdevelopment, Raúl Prebisch, Ragnar Nurkse, Celso Furtado.

\section{Introdução}

A importância de Celso Furtado para o pensamento econômico no Brasil é reconhecida no meio acadêmico nacional e internacional. Em

\footnotetext{
* Este texto é uma reprodução parcialmente modificada do artigo intitulado "Inadequação Tecnológica e Subdesenvolvimento: As Abordagens de Raúl Prebisch, Ragnar Nurkse e Celso Furtado nos Anos 50", apresentado no VII Encontro Nacional de Economia Política, 28 a 31 de maio, Curitiba, 2002.
} 
obras como Formação Econômica do Brasil (1959), Desenvolvimento e Subdesenvolvimento (1961), Teoria e Política do Desenvolvimento Econômico (1967), Furtado apresentou um método de análise e um amplo referencial de estudo de importantes aspectos da evolução da economia brasileira ao longo do tempo.

Uma característica do seu aporte teórico é a tentativa de integrar a Economia, a Política e a História, o que lhe conferiu uma visão particular da dinâmica econômica, distanciada da abordagem "a-histórica" da teoria do equilíbrio geral. A criação da CEPAL, em 1948, foi um passo importante na elaboração de uma teoria do subdesenvolvimento e de uma estratégia heterodoxa de superação do atraso econômico - em contraponto às propostas apoiadas na teoria das vantagens comparativas. A contribuição teórica de Celso Furtado e o seu trabalho de divulgação destas idéias são inquestionáveis.

O objetivo deste texto é resgatar as idéias predominantes nas análises de Raúl Prebisch, Ragnar Nurkse e Celso Furtado, no início dos anos 50, a respeito da relação entre progresso técnico e subdesenvolvimento. A intenção não é explorar todos os aspectos das contribuições de Prebisch e de Nurkse para o tema; mas apenas identificar, nas reflexões destes dois importantes autores, contemporâneos de Furtado, indícios de que algumas das suas idéias poderiam ser contrapostas e/ou complementadas pelas idéias de Prebisch e de Nurkse. Este resgate contribui para uma visão retrospectiva da evolução das idéias de Furtado sobre a relação entre progresso técnico e subdesenvolvimento.

O texto está dividido em quatro seções: as três primeiras foram reservadas para as abordagens da relação entre progresso técnico e subdesenvolvimento, formuladas por cada um dos três autores, em trabalhos datados dos anos 50. A quarta e última seção traz uma síntese das semelhanças e das eventuais diferenças de ênfases das respectivas abordagens.

\section{A concepção Prebisch-CEPAL de progresso técnico e o problema da adaptação da tecnologia}

Progresso técnico e homogeneização da estrutura econômica

No artigo "Interpretação do processo de desenvolvimento econômico" (1951)', Prebisch afirmou que as técnicas intensivas em capital

O Estudo de 1949 foi apresentado na conferência da CEPAL em Montevidéu, no mês de maio de 1950. Furtado afirmou, na Fantasia Organizada (1985), que os cinco 
resultaram de um longo processo de evolução dos centros industriais, onde o aumento do salário real teria estimulado a criação de inovações tecnológicas destinadas a substituir trabalho por capital. A pressão da acumulação sobre o emprego tendeu a elevar os salários reais, induzindo a adoção de técnicas "poupadoras de trabalho", o fator escasso nas economias avançadas. A viabilidade econômica dos investimentos que incorporavam estas técnicas, segundo Prebisch, é explicada pelo fato de que as despesas adicionais com capital - em termos de amortização e juros - eram compensadas pela redução dos custos com salários, devido à economia de mão-de-obra que as técnicas altamente capitalizadas proporcionavam. Pelas palavras do autor:

"Sabemos que o equipamento moderno, exigindo maior inversão de capital per capita, só é econômico quando o total dosjuros e da amortização correspondentes é inferior à redução proporcionada pela nova dotação nos outros custos. Para fins de brevidade, vamos apenas considerar a redução da mão de obra. A elevação progressiva dos salários, resultante do aumento da produtividade, foi talvez o fator de maiorimportância entre aqueles que determinaram a conveniência de se continuar a aumentar a inversão de capital per capita por meio de sucessivos melhoramentos técnicos. Pois, uma vez generalizada a nova dotação de capital, devido ao novo nível dos salários, não resultaria econômico para nenhuma empresa nova empregar dotações menores, correspondentes a um nível de salários inferior" (Prebisch, 1951:91).

Na visão de Prebisch, o desemprego gerado pelas técnicas "poupadoras de trabalho" foi compensado pela expansão da indústria de bens de capital, isto é, pelo aumento dos investimentos, estimulados pelos novos procedimentos de produção. Assim, uma nova pressão da acumulação sobre os salários reais desencadearia a incorporação de um novo fluxo

primeiros capítulos deste trabalho foram redigidos por Raúl Prebisch e levaram o título geral de "Crescimento, desequilíbrios e disparidades: interpretação do processo de desenvolvimento econômico". A tradução deste trabalho de Prebisch, feita por Furtado, foi publicada na Revista Brasileira de Economia, v. 5, n. 1, março, 1951, com o título de "Interpretação do processo de desenvolvimento econômico". Este texto, juntamente com os Problemas Teóricos e Práticos do Crescimento Econômico (1973), apresentado na conferência da CEPAL no México, em maio de 1951, são as referências da contribuição de Raúl Prebisch utilizadas para abordar o tema desta seção. 
de inovações, com técnicas ainda mais intensivas em capital, caracterizando o mecanismo de aumento da densidade de capital nos centros industriais. O progresso técnico gerou desemprego da mão-de-obra nos setores em que as técnicas "poupadoras de trabalho" avançavam rapidamente, mas estimulou novos investimentos e a absorção da mãode-obra no setor de bens de capital:

"Essas influências desfavoráveis ao emprego e aos salários acarretam freqüentemente reações contrárias ao progresso técnico durante o desenvolvimento dos grandes países industriais. Mas esse mesmo progresso, ao exigir crescentes inversões de capital, vai criando nesses países um poderoso elemento de absorção do desemprego, qual seja o desenvolvimento das indústrias de bens de capital. O progresso técnico, por conseguinte, provoca o desemprego mas ao mesmo tempo tende a reabsorver essa mão de obra, em virtude do aumento das inversões.Tal foi a função que estas desempenharam espontaneamente no desenvolvimento dos centros industriais, pelo menos até a crise mundial" (Prebisch, 1951:90).

Por outro lado, a elevação do salário real, acompanhando a produtividade do trabalho, não teria desestimulado a acumulação porque, segundo Prebisch, o progresso técnico elevou também a produtividade do capital, de modo a manter a sua remuneração em níveis compatíveis com a continuidade da acumulação. Nos Problemas Teóricos e Práticos do Crescimento Econômico (1973), o autor enfatizou que as inovações intensivas em capital aumentaram simultaneamente, ainda que em ritmos diferentes, as produtividades do trabalho e do capital, tornando impossível classificar, com precisão, as inovações "poupadoras de trabalho" (que elevam a produtividade do trabalho e a densidade do capital) e as "poupadoras de capital". Afirmou-se:

"É certo que a evolução tecnológica também aumenta a quantidade de produção por unidade de capital ao mesmo tempo que se poupa mão-de-obra. Se bem que ambos os objetivos tenham determinado investimentos crescentes de capital por trabalhador, e embora se os possa separar em abstrato, o desenvolvimento tecnológico os foi combinando de tal forma que, em geral, não seria possível determinar que parte dos investimentos responde ao objetivo de aumentar a quantidade de produção por unidade de capital e que parte corresponde a uma economia de mão-de-obra [...]. 
Desse modo, dada a forma simultânea em que ambos os objetivos foram se implementando, e dada a indivisibilidade dos equipamentos em que se concretiza o processo tecnológico, as combinações a que se chegou na economia de um país altamente industrializado e de alto capital por pessoa não podem desfazer arbitrariamente e transformar-se em outras combinações que se adaptem melhor à realidade de um país menos desenvolvido, e de disponibilidade de capital por pessoa muito inferior" (Prebisch, 1973: 37-9).

Para Prebisch, a tecnologia moderna se caracteriza pela elevada densidade de capital, rigidez ou indivisibilidade das escalas de produção e impossibilidade de substituição dos fatores de produção. O progresso técnico gerou processos produtivos intensivos em capital e escalas de produção com dotações mínimas de capital compatíveis com o nível de renda e a dimensão do mercado nas economias industrializadas. A própria elevação dos salários com base nos ganhos de produtividade, segundo o autor, teria contribuído para expandir o mercado interno e viabilizado a produção em larga escala da técnica moderna.

Em resumo, os aumentos dos salários impulsionaram a intensificação do capital, enquanto a elevação da produtividade permitiu a elevação dos salários nos setores de maior dinamismo tecnológico. Por sua vez, os salários elevados tenderam a se propagar para os demais setores e ramos da produção devido à mobilidade dos fatores. A homogeneização tecnológica da estrutura produtiva resultou, em boa parte, deste processo, pois, na visão de Prebisch, a elevação do salário real inviabilizava a adoção de técnicas de menor coeficiente de capital, estimulando a expansão do investimento e do setor de bens de capital e reduzindo os desníveis de produtividade da estrutura produtiva:

"De outra parte, à medida que a mobilidade dos fatores produtivos vai estendendo a majoração de salários às demais atividades, não se pode conceber que, històricamente, certas indústrias aumentem consideràvelmente sua inversão de capital per capita, por meio do emprego de maquinaria cada vez mais moderna, e que outras continuem a funcionar com dotações de capital relativamente menores, apesar de talvez ser esta a solução mais econômica, porquanto o progresso técnico tende a estender-se. Quanto maior fôr a mobilidade dos fatôres produtivos maior será a correlação entre o desenvolvimento dos diversos setores da atividade econômica, do ponto de vista da inversão de capital por operário empregado" (Prebisch, 1951:91-2). 
Assim, a propagação dos aumentos de salários para o conjunto do sistema econômico estimulou o avanço tecnológico e teria sido fundamental para a homogeneização dos níveis de produtividade, isto é, para a redução das disparidades tecnológicas, em particular entre as atividades industriais e as agrícolas. Para Prebisch, o progresso técnico na agricultura foi altamente estimulado pelo aumento dos salários, possibilitado pelos ganhos de produtividade e pelo crescimento da indústria, que, absorvendo grande parte da mão-de-obra, forçou a modernização da agricultura:

"O desenvolvimento das atividades manufatureiras e outras [...] foi absorvendo uma parte crescente do incremento da população e forçando a produção primária a realizar constantes melhoramentos na sua técnica. O progresso técnico da agricultura, por conseguinte, foi, em grande parte, a conseqüência do desenvolvimento industrial" (Prebisch, 1951:89).

Na agricultura, segundo Prebisch, o progresso técnico deu origem a diferentes alternativas tecnológicas, duas a destacar: a mecanização do trabalho, que reduziria a quantidade de trabalho por unidade de produto e por unidade de superfície, sem alterar a produtividade do solo, constituindo "o meio pelo qual se vai criando o excedente de população que a indústria e outras atividades terão que absorver produtivamente" (Prebisch, 1973:47). A mecanização permitiria então o deslocamento da mão-de-obra da agricultura para a indústria, satisfazendo o aumento da demanda por trabalho do conjunto do sistema econômico.Já as tecnologias "poupadoras de capital" tendem a aumentar os rendimentos por hectare mediante o melhoramento técnico dos procedimentos de cultivo, desde a seleção de sementes até o emprego de pesticidas; e aqueles outros, tendentes a aumentar a superfície aproveitável mediante obras de irrigação e drenagem, de florestamento e recuperação de terrenos prejudicados pela erosão, ou a evitar que esta diminua a superfície atual da produção" (Prebisch, 1973:51). Estas técnicas de menor densidade de capital, segundo o autor, empregam mais trabalho, elevam relativamente a produtividade do capital e da terra e contribuem para a expansão da oferta agrícola, atendendo à maior demanda, gerada pelo crescimento econômico. A conclusão de Prebisch é de que, na agricultura, os coeficientes técnicos são menos rígidos e os problemas de indivisibilidade de escala são menos significativos do que na indústria,pois a disponibilidade de alternativas tecnológicas confere maior flexibilidade à combinação dos fatores de produção. Na agricultura, seria possível aplicar técnicas com a finalidade de elevar a oferta agrícola para atender às necessidades criadas pelo crescimento econômico, be m como deslocar mão-de-obra para atender à demanda de trabalho do conjunto do sistema econômico. Ressalte-se que esta idéia sustenta o seu argumento de que a maximização da produção e do emprego na periferia é principalmente dificultada pela estrutura de posse e propriedade da terra.Ver Prebisch (1973) e a interpretação de Rodríguez (1981). 
Ao analisar os contrastes entre o desenvolvimento do centro e da periferia, Prebisch relacionou o limitado acesso das economias periféricas ao progresso técnico com a inserção exportadora de produtos primários na divisão internacional do trabalho e, por conseqüência, com o longo período transcorrido entre a Revolução Industrial e a industrialização da América Latina. É amplamente conhecido o argumento de que, quanto maior o atraso dos países periféricos na incorporação das técnicas modernas, mais profundas as disparidades entre os níveis de produtividade e de renda e as necessidades de capital para viabilizar o desenvolvimento econômico. Isto ocorreria porque o progresso técnico assimilado pela periferia não é fruto de um lento processo de aumento da produtividade e da renda, que traria a conseqüencia de elevar a disponibilidade de poupança para a formação de capital:

"Nos países de grande desenvolvimento, a técnica de produção exige vultosa quantidade de capital por operário; em compensação, o crescimento gradual da produtividade, devidojustamente à introdução dessa técnica, proporcionou a êsses países uma renda elevada per capita, mediante a qual puderam realizar a poupança necessária à formação dêsse capital. [...] Analisando bem, verifica-se que o nível de poupança não é alto ou baixo em si mesmo, e sim em relação à densidade de capital resultante do progresso técnico. Nesse sentido o nível de poupança na América Latina é, geralmente, muito baixo, em relação às necessidades da técnica moderna. Não resta dúvida que, no princípio da evolução industrial dos grandes países, a poupança espontânea tampouco foi vultosa, mas em compensação, a técnica não exigia o grande coeficiente de capital, por operário, que atualmente requer. [...]

Compreende-se, por conseguinte, que, quanto mais tarde se introduzir a técnica moderna num país periférico, mais violento será o contraste entre a limitada quantia de sua renda per capita e o vulto do capital necessário para poder aumentar essa renda rapidamente. $[\ldots]$

Por conseguinte, os países que empreenderam, há pouco, o seu desenvolvimento industrial, gozam, de uma parte, da vantagem de encontrarem uma técnica que, nos grandes centros, foi obtida à custa de muito tempo e sacrifício. Mas, de outra parte, encontram todas as desvantagens inerentes ao fato de que seguem com atraso a evolução dos acontecimentos" (Prebisch, 1951: 86-7). 
Inadequação tecnológica e desemprego estrutural

Foi visto que, na concepção de Prebisch, o progresso técnico eleva a densidade de capital, aumentando simultaneamente e em ritmos diferentes a produtividade do trabalho e do capital ${ }^{3}$.

Para Rodríguez (1981), esta concepção do progresso técnico sustenta a idéia cepalina de que o pleno emprego (da força de trabalho e da capacidade produtiva instalada) requer o aumento da taxa de acumulação - definida como o produto da taxa de poupança"s" pela produtividade do capital"k" - no mesmo ritmo da taxa de crescimento da população economicamente ativa "e". A explicação do autor é a seguinte: como o progresso técnico eleva a produtividade do capital "k", se a taxa de crescimento da população ativa "e" for constante, o esforço de acumulação "s", necessário para preservar o pleno emprego, é menor, à medida que o progresso técnico eleva a densidade de capital nas economias avançadas. Assim, uma estrutura econômica homogênea - com reduzidas disparidades tecnológicas e de níveis de produtividade - não apresentaria tendência ao desemprego estrutural, nem exigiria um grande esforço de poupança para manter o pleno emprego, ao longo do processo de desenvolvimento ${ }^{4}$.

3 A concepção Prebisch-CEPAl de progresso técnico é formalizada por Rodríguez. (1981) através de uma função de produção linear de coeficientes técnicos fixos, da qual deriva que a densidade de capital $(\mathrm{K} / \mathrm{T})$ é igual ao quociente cntre a produtividade do trabalho " $t$ " $e$ a produtividade do capital " $k$ ". Como não há possibilidade de substituição dos fatores de produção (as proporções são fixas), para cada quociente entre as produtividades do trabalho e do capital $(\mathrm{t} / \mathrm{k})$ corresponde uma única dotação de capital por trabalhador $(\mathrm{K} / \mathrm{T})$. A demonstração é a seguinte: dadas as funçōes lineares com coeficientes técnicos fixos: $\mathrm{P}=\mathrm{k} \cdot \mathrm{K}$ (1) e $\mathrm{P}=\mathrm{t}$. T (2), onde " $\mathrm{P}$ " ć o produto real; " $K$ " $e$ " $T$ " são as quantidades físicas de capital e de trabalho; e " $k$ " e " $t$ " são as respectivas produtividades médias (iguais às produtividades marginais); a dotação de capital por trabalhador é obtida igualando as equaçōes (1) e (2): $\mathrm{k} . \mathrm{K}=\mathrm{t}$. $\mathrm{T}$, do qual resulta $\mathrm{K} / \mathrm{T}=\mathrm{t} / \mathrm{k}$. Assim, a densidade de capital aumenta à medida que a produtividade do trabalho cresce mais rapidamente que a produtividade do capital. Uma implicação importante é que "o surgimento de novas tecnologias determina a obsolescência das anteriormente existentes, já que, por definição, as primeiras permitem um uso mais eficiente dos recursos, do ponto de vista técnico" (Rodríguez, 1981: 101).

4 Segue a demonstração formalizada: supondo o pleno emprego, o equilíbrio no mercado de trabalho seria dado pela igualdade:" $\mathrm{K}^{:+1} \mathrm{~m} / \mathrm{t}=\mathrm{e} . \mathrm{F}_{\mathrm{m}}^{\mathrm{n}}(1)$, onde $\mathrm{k} / \mathrm{t}$ é o inverso da densidade de capital e indica a magnitude do emprego por unidade de capital; "Kn+1 ${ }_{m}$ é o investimento que se incorpora à produção no período $(n+1) ; \mathrm{F}^{n}{ }_{m}$ 
Em contraste, o desemprego nas economias periféricas é de tipo estrutural e se deve à heterogeneidade da estrutura econômica e à inadequação tecnológica, conforme descreveu Prebisch:

"(...) nos países menos desenvolvidos, onde há escassez de capital para absorver com intensidade aquele potencial humano de produtividade inferior, uma economia excessiva de mão-de-obra em novos investimentos de capital ou nas renovações de equipamentos contribui para tornar mais agudo o problema estrutural. [...]

Estes equipamentos, comojá foi dito, correspondem a altas rendas e elevada capacidade de poupança. Em contrapartida, nos países menos desenvolvidos, não guardam nenhuma relação com as rendas relativamente baixas e a escassa capacidade de poupança que os caracteriza. E se há empresários que estão em condições de adquiri-los, isso não significa, de modo algum, que haja capital disponível para generalizar seu emprego" (Prebisch, 1973: 42).

Para Prebisch, as economias periféricas se caracterizam pela heterogeneidade estrutural, isto é, pela coexistência do setor arcaico com o setor moderno e, portanto, pelas disparidades de nível técnico, de pro-

é o nivel de emprego no periodo anterior " $n$ ", e "e" é a taxa de crescimento da população ativa. A demanda adicional de mâo-de-obra no setor moderno é determinada pelo produto da demanda unitária de trabalho pelo investimento que se incorpora à produção no período $(n+1):\left({ }^{\prime \prime} \mathrm{K}^{\mathrm{n}+1} \mathrm{~m} \cdot \mathrm{k} / \mathrm{t}\right)$, enquanto a oferta adicional de trabalho é o produto do emprego no período anterior $\left(E^{n}{ }_{m}\right)$ pela taxa de crescimento da população ativa supostamente constante (e. $\mathrm{E}^{n}{ }_{m}$ ).

O pleno emprego da capacidade instalada e da força de trabalho, sustentado pela igualdade macroeconômica entre poupança e investimento $I=S$, expressa-se por: " $\mathrm{K}_{\mathrm{m}}^{n+1}=\mathrm{P}$ ". $s(2)$, onde "Pr" é o produto real no período " $n$ ", "s" é a taxa de poupança e o produto ( $\mathrm{P}^{\mathrm{n}}$. $\mathrm{s}$ ) corresponde à poupança no periodo " $\mathrm{n}$ ". Como na função de produção de coeficientes fixos, o produto real é dado por $\mathrm{P}^{\mathrm{n}}=\mathrm{k} \cdot \mathrm{K}^{\mathrm{n}}{ }_{\mathrm{m}}$ (3), substituindo (3) em (2) obtém-se " $\mathrm{K}^{\mathrm{n}+1}=\mathrm{s} \cdot \mathrm{k} \cdot \mathrm{K}^{\mathrm{n}}{ }_{\mathrm{n}}$ (4), de onde se extrai que a taxa de variação do estoque de capital " $\mathrm{K}^{\mathrm{n}+1}{ }_{m}^{m} / \mathrm{K}^{\mathrm{n}}{ }_{\mathrm{m}}={ }_{\mathrm{s}}^{\mathrm{n}} \mathrm{s} \cdot \mathrm{k}$ é diretamente proporcional à taxa de poupança e à produtividade do capital. Substituindo-se (4) cm (1) temos: $\mathrm{K}_{m}^{\mathrm{n}} \mathrm{s} \cdot \mathrm{k} \cdot \mathrm{k} / \mathrm{t}=\mathrm{e} \cdot \mathrm{E}_{\mathrm{m}}^{\mathrm{n}} \mathrm{e}$, dividindo por $\left(\mathrm{E}^{\mathrm{n}}{ }_{\mathrm{m}}\right)$, obtén-se: $\mathrm{K}^{\mathrm{n}}{ }_{\mathrm{m}} / \mathrm{E}^{\mathrm{n}}{ }_{\mathrm{m}} \mathrm{s} \cdot \mathrm{k} \cdot \mathrm{k} / \mathrm{t}=\mathrm{e}$. Como a densidade de capital equivale ao quociente entre as produtividades do trabalho " $\mathrm{t}$ " c do capital " $\mathrm{k}$ ", chega-se à igualdade $\mathrm{K} "{ }_{11} / \mathrm{F}^{\mathrm{n}}=\mathrm{t} / \mathrm{k}$, de modo que o equilíbrio dinâmico do mercado de trabaltıo (supondo o pleno emprego) é dado por:s.k = e. A taxa de acunulação de capital (s.k) deve crescer no mesmo ritmo que a taxa de crescimento da população ativa " $\mathrm{e}$ " para preservar o pleno emprego.Ver Rodríguez (1981). 
dutividade e de renda. O setor arcaico não absorveria a oferta adicional de trabalho, proveniente do crescimento vegetativo da população, de modo que o aumento da população economicamente ativa nos dois setores teria que ser absorvido pelo setor moderno. Por outro lado, o aumento da densidade de capital e da produtividade do capital no setor moderno - que, na visão de Prebisch, favorece a acumulação e o emprego - não seria suficiente para ocupar a força de trabalho adicional, originada de ambos os setores. O desemprego estrutural se manifestaria, então, por meio do desajuste entre o ritmo de acumulação (determinado pela taxa de poupança e pela produtividade do capital no setor moderno) e o crescimento da força de trabalho, o que está relacionado com a importância relativa dos setores arcaico e moderno, que coexistem nas economias periféricas. Conforme observa Rodríguez (1981):

"A heterogeneidade estruturaljoga um papel-chave na explicação da tendência ao desemprego, peculiar às economias periféricas. Pode-se considerar que a coexistência de setores modernos e atrasados afeta as variáveis demográficas, refletindo-se numa alta taxa de aumento da população e da população ativa. Por outro lado, a maior proporção da força de trabalho ocupada nas atividades arcaicas eleva o ritmo de crescimento da oferta global de mão-de-obra, em relação ao emprego no setor moderno. A expansão da demanda tende a ser insuficiente, em comparação com o forte ritmo de aumento da oferta: o esforço de poupança só se realiza neste último setor, cujas dimensões e níveis de renda média são relativamente pequenos" (Rodríguez, 1981: 104).

Já a argumentação de Prebisch em torno da relação tecnologia e desemprego estrutural na periferia é sintetizada por Rodríguez (1981), como segue:

"A acumulação da periferia é exígua, devido aos seus baixos níveis de produtividade e renda; a traduzir-se em investimentos de elevada densidade de capital e grande escala, mostra-se insuficiente para absorver produtivamente uma oferta de força de trabalho de dimensões consideráveis; oferta que provém, por um lado, do crescimento vegetativo da população e, por outro, do deslocamento de mão-deobra a partir de setores de baixa produtividade, em conseqüencia do desemprego tecnológico provocado por esses mesmos investimentos" (Rodríguez, 1981: 78). 
Assim, a pequena dimensão do setor moderno, expressão da heterogeneidade estrutural, tornaria o seu esforço de acumulação insuficiente para absorver a oferta de trabalho resultante do crescimento da população ativa. Acrescente-se a isto o problema da inadequação tecnológica - de densidade e de escala - que, segundo Prebisch, além de gerar desemprego tecnológico, dificultaria a absorção da oferta total de mão-de-obra pelo setor moderno. Rodríguez (1981) faz o seguinte comentário sobre o problema da inadequação tecnológica na concepção Prebisch-CEPAL:

"(...) a tendência ao desemprego pode, com propriedade, ser chamada de 'estrutural', pois ela é considerada um resultado natural e espontâneo de transformações de estrutura que constituem e tornam peculiar a industrialização das economias periféricas: a modificação da importância relativa de seus setores produtivos, através da acumulação nos setores modernos, adotando técnicas cuja densidade de capital é muito maior que a dos setores e ramos atrasados, e cuja escala está desajustada em relação aos níveis de renda e às dimensões do mercado próprios desse tipo de economia" (Rodríguez, 1981: $86)$.

É importante ressaltar, recorrendo mais uma vez à contribuição de Rodríguez (1981), que o conceito de inadequação tecnológica que Prebisch utilizou para analisar o desemprego estrutural baseia-se na distinção entre inadequação de densidade de capital e inadequação de escala de produção. A inadequação de densidade geraria desemprego tecnológico, aumentando a oferta de mão-de-obra, não obstante a incidência favorável das técnicas mais avançadas sobre a acumulação e o emprego no setor moderno. A inadequação de escala desestimularia a acumulação e a demanda de trabalho, pois a capacidade ociosa tende a reduzir a produtividade do capital. Assim, para uma dada parcela do investimento que compete com o setor arcaico, o desemprego tecnológico seria tanto maior quanto maior fosse o emprego de trabalho por unidade de capital no setor atrasado. Por conseqüencia, com o aumento da densidade de capital no setor moderno, o crescimento da oferta de trabalho (fruto do desemprego tecnológico) tenderia a superar o aumento da demanda de trabalho no próprio setor moderno. Daí a necessidade, de acordo com Prebisch, de elevar a taxa de poupança nas economias subdesenvolvidas, a fim de que o maior esforço de acumulação pudesse absorver a oferta de trabalho, gerada pelo desemprego tecnológico e pelo crescimento da população economicamente ativa. 


\section{A visão de Raúl Prebisch sobre a adaptação da tecnologia}

Para Rodríguez (1981), a distinção entre inadequação de densidade de capital e de escala de produção predomina e diferencia a abordagem Prebisch-CEPAL da concepção de inadequação tecnológica, formulada com base no conceito de densidade ótima do capital. Este conceito, segundo o autor, associa diretamente o aumento da densidade de capital do investimento à redução da demanda de trabalho, sob o argumento de que a tecnologia de elevada densidade de capital - inadequada diante da escassez relativa de capital e abundância de mão-de-obra - impediria que a periferia alcançasse os mesmos níveis de produção e emprego, obtidos com as técnicas de densidade ótima, geradas no centro. Daí a recomendação de adaptar a tecnologia, seja através de alternativas de investimentos com técnicas de menor densidade de capital, seja através da criação de tecnologias de menor densidade de capital, mais adequadas à disponibilidade de fatores da periferia.

Em contraste, na interpretação de Rodríguez (1981), a total impossibilidade de substituição dos fatores e a indivisibilidade do capital ou rigidez de escala, presentes na caracterização de Prebisch do progresso técnico, tornariam as técnicas modernas pouco adaptáveis. Além disto, como o progresso técnico eleva simultaneamente as produtividades do trabalho e do capital, as técnicas de menor densidade de capital — se disponíveis - tenderiam a se tornar obsoletas. Sobre este ponto, Rodríguez (1981) opina:

"Sem negar validez a estas recomendações [a adaptação tecnológica], na análise cepalina admite-se que a existência de alternativas de investimento com diferentes densidades de capital é muito pouco freqüente; e que o avanço tecnológico gera técnicas mais modernas e de maior densidade de capital que suplantam as mais antigas, de densidade menor, devido à maior eficácia das primeiras. Daí se depreende que o uso de técnicas atrasadas e obsoletas, ainda que pudesse favorecer o emprego, produziria forçosamente um menor nível de renda. Conclui-se que a maximização simultânea de emprego e produto, a longo do processo de desenvolvimento, não seria conquistada com a incidência sobre a densidade de capital, mas sim com a distribuição adequada dos investimentos realizados no setor moderno entre atividades competitivas e não-competitivas com a produção preexistente. Ou seja, tratando-se de distribuí-las de maneira a minimizar os problemas de escala e, ao mesmo tempo, de lograr que a 
expulsão líquida de mão-de-obra provocada pelos investimentos competitivos, somada ao crescimento da população ativa, seja compatível com a absorção alcançada através dos investimentos não-competitivos" (Rodríguez, 1981: 87).

$\mathrm{Na}$ análise de Prebisch, predominaria então a idéia de que a densidade ótima não é alcançável com as modernas técnicas industriais, porque são pouco adaptáveis à disponibilidade de capital na periferia. Por isto, a recomendação principal não vai no sentido de alterar a densidade de capital da tecnologia assimilada, mas sim no de distribuir os investimentos entre os setores moderno e arcaico, reduzindo os efeitos do desemprego tecnológico sobre a absorção da economia de subsistência e,por conseqüência, sobre a restrição da dimensão do mercado interno em relação à escala de produção.

É importante destacar, porém, que, mesmo que não tenham sido predominantes no pensamento Prebisch-CEPAL - e sem lhes negar validade como ressalva Rodríguez - a inadequação tecnológica, fundada no conceito de densidade ótima, e a defesa da adaptação da tecnologia estiveram presentes nas elaborações iniciais de Raúl Prebisch e de Celso Furtado, como será visto mais adiantes.

"No artigo "Interpretação do processo de desenvolvimento econômico" (1951), Prebisch defendeu a necessidade de técnicas de menor densidade de capital para a periferia, utilizando-se, aparentemente, do conceito de densidade ótima de capital:

"O fato de determinado equipamento novo ser mais econômico do que outro, num centro, porque a economia adicional de mão-de-obra compensa sobejamente as correspondentes despesas de amortização ejuros, não quer dizer que também seja mais econômico num país periférico de salários inferiores, que teria que importar o referido equipamento daquele centro. [...] Ou melhor, o pais periférico estaria importando equipamento de capital fabricado com salários elevados para obter uma redução de custo computado em salários baixos.

Destarte, nos países periféricos o custo do capital aumenta mais do que nos centros, à medida que a densidade de capital per capita é incrementada, enquanto que a redução do custo da mão-de-obra é menor dado o nível inferior dos salários.Verifica-se, assim, que a combinação ótima entre mão-de-obra e dotação de capital, nos países menos desenvolvidos, exigirá um grau de densidade de capital por operário menor que nos países de intenso desenvolvimento industrial; e quanto mais marcante o desnível entre os respectivos níveis de salários ejuros, menor deve ser o aludido grau de densidade de capital na igualdade de outros fatores que não aludimos, por motivos de simplificação" (Prebisch, 1951: 92-3).

Já nos Problemas Teóricos e Práticos do Crescimento Econômico (1973), Prebisch fez as 


\section{A inadequação tecnológica e o "círculo vicioso da estagnação" na concepção de Ragnar Nurkse ${ }^{6}$}

Ragnar Nurkse definiu o desenvolvimento econômico como um fenômeno "estreitamente ligado a aptidões humanas, atitudes sociais, condições políticas e acontecimentos históricos" (Nurkse, 1951: 11). Contudo, a base do desenvolvimento é a acumulação de capital, que permite incorporar progresso técnico:

"A essência do progresso, então, é o desvio de uma parte dos recursos da sociedade correntemente disponíveis para o fim de aumentar o estoque de bens de produção, de modo a tornar possível uma expansão da produção de bens consumíveis no futuro [...]. Quando o estoque de capital aumenta, naturalmente sua forma técnica se modifica [...]. A forma técnica do capital se modifica à medida que o suprimento de capital por operário se altera [...]. É um fenômeno [o progresso técnico] interessante e importante, mas meramente um aspecto mecânico do aumento do estoque de bens de produção" (Nurkse, 1951: 12-3).

O progresso técnico "significa a construção de mais e melhores instrumentos de produção e a utilização, para este fim, de uma parcela maior do acervo de conhecimentos técnicos existentes" (Nurkse, 1951:

seguintes considerações sobre a necessidade das técnicas de menor densidade de capital e as dificuldades para a adaptação das tecnologias assimiladas do centro:

Dada a relativa escassez de capital e a relativa abundância de potencial humano que prevalece nesse tipo de países, é possível conceber uma densidade ótima de capital menor do que nos países mais desenvolvidos. Mas, dada a natureza do progresso técnico e sua irreversibilidade, os países menos desenvolvidos não têm muitas possibilidades de buscar, na prática, a qualidade ótima que lhes seria correspondente. Certamente que, em alguns casos, lhes é dado empregar equipamentos menos complexos e outros procedimentos atrasados que requerem pouco capital;porém, se, em virtude da eficácia produtiva muito inferior destes procedimentos, propõem-se a modernizar seus equipamentos, vêem-se obrigados, com freqüencia, a adquirir os de alta densidade, uma vez que, dada a natureza da técnica empregada, cada equipamento é, geralmente, indivisível e sua densidade não poderia ser rebaixada até se ver reduzida a um nível adequado a um capital relativamente escasso" (Prebisch, 1973:36-7, grifos nossos).

As conferências de Ragnar Nurkse realizadas no Brasil, no período de julho a agosto de 1951, publicadas na Revista Brasileira de Economia, v. 5, n. 4, 1951, com o título "Formação de capital em países subdesenvolvidos" (1951), são as referências bibliográficas utilizadas nesta seção. 
13).De acordo com este autor, o conhecimento científico tem relevância econômica quando a sua aplicação no processo produtivo permite elevar a eficiência da produção. Por isto, as inovações tecnológicas estariam prioritariamente orientadas para "poupar trabalho", que é o fator escasso nas economias desenvolvidas. Além de intensivas em capital, as técnicas "poupadoras de trabalho" operam com elevada escala de produção. Es tas tecnologias estariam disponíveis para as economias subdesenvolvidas, mas a escassez de capital dificultava a sua aplicação à produção, isto é, a sua incorporação ao estoque de capital. Afirmou o autor:

"Deixando de lado os aspectos mecânicos da formação de capital, tomarei como aceita a hipótese - hipótese bastante realista, especialmente para os países subdesenvolvidos — de que há no mundo um grande fundo de conhecimentos técnicos, que poderiam ser aplicados vantajosamente ao processo da produção, se houvesse capital disponível para utilizá-1os" (Nurkse, 1951: 13).

A interpretação de Nurkse sobre as restrições à formação de capital nas economias subdesenvolvidas é a seguinte: os baixos níveis de produtividade estão relacionados com a pequena quantidade de capital por trabalhador, aplicada à produção, e com o reduzido incentivo para investir, devido à pequena dimensão real do mercado interno, que é reflexo da baixa produtividade e do baixo poder aquisitivo da população subocupada na economia de subsistência. Isto acabaria por desestimular a acumulação, pois a excessiva capacidade ociosa reduziria a produtividade do capital, inviabilizando os investimentos que incorporam as técnicas avançadas de alta densidade de capital e elevada escala de produção:

"O incentivo econômico para instalar equipamento para a produção de uma certa mercadoria ou serviço depende sempre, numa certa medida, da quantidade de trabalho a ser feito com êste equipamento [...]. O tamanho limitado do mercado interno num país subdesenvolvido constitui um obstáculo à aplicação de capital por qualquer empresa privada que trabalhe para esse mercado. Neste sentido, o pequeno mercado interno é geralmente um obstáculo ao desenvolvimento" (Nurkse, 1951: 16).

A dimensão real do mercado interno ou o seu tamanho econômico, segundo Nurkse, é função do nível de produtividade, que depende, "em grande parte (de nenhum modo inteiramente, mas grandemente), 
da quantidade de capitais usados na produção. A produtividade é principalmente uma questão de uso de maquinaria e outros tipos de equipamento" (Nurkse, 1951:17). Como o incentivo para investir depende do poder aquisitivo do mercado interno, mas os baixos níveis de produtividade resultam da pequena quantidade de capital aplicado à produção, devido à pequena dimensão do mercado, conclui-se que há um conjunto de forças tendentes a manter qualquer economia na condição de "equilíbrio de subdesenvolvimento". Assim, para Nurkse,"o progresso não é uma ocorrência espontânea ou automática. Pelo contrário, as forças automáticas dentro do sistema tendem a manter a economia em uma condição estacionária" (Nurkse, 1951:18). O conjunto de forças que caracteriza o "círculo vicioso da estagnação" está expresso pela seguinte relação de causalidade:

"O incentivo para o uso de capital é limitado pelo pequeno tamanho do mercado; o pequeno tamanho do mercado é devido ao baixo nível de produtividade; o baixo nível de produtividade é devido à pequena quantidade de capital usado na produção, à qual, por sua vez, é devida ao pequeno tamanho do mercado-e, assim, o círculo está completo" (Nurkse, 1951: 18).

$\mathrm{Na}$ abordagem de Nurkse, a ampliação do mercado interno nas economias subdesenvolvidas exigiria a absorção da população ocupada no setor de subsistência, elevando o nível de produtividade e o poder aquisitivo do conjunto da população, através da acumulação e do aumento da quantidade de capital aplicada à produção. Ocorre que os investimentos são desestimulados pela própria limitação do mercado interno. Neste sentido, pode-se argumentar que a inadequação de escala constituiria, na visão de Nurkse, um importante obstáculo à acumulação, à absorção da economia de subsistência, ao aumento da produtividade e do poder aquisitivo da população.

Porém Nurkse atribuiu às "ondas de investimento" o poder de romper com as forças estacionárias do subdesenvolvimento, ao criar a mais importante das economias externas - geradora de lucros crescentes ao longo do processo de desenvolvimento - que é a expansão do potencial aquisitivo do mercado interno. O argumento completo é o seguinte:

"Onde qualquer empreendimento isolado pode ser fatalmente impraticável e não lucrativo, um grande número de investimentos simultâneos, abrangendo grande número de indivíduos diferentes 
pode ser bem sucedido porque todos se apoiarão mutuamente, no sentido de que o pessoal empregado em determinado empreendimento, trabalhando com equipamento melhor e mais abundante, assegurará um mercado ampliado para os produtos dos novos empreendimentos nessas outras indústrias. Um empreendimento isolado, como uma fábrica de calçados, em um país subdesenvolvido pode ser, tècnicamente, de eficiência muito elevada e, contudo, ser econômicamente um insucesso, porque o pessoal que trabalhar nessa fábrica despenderá, apenas, uma parte de seu salário nos produtos da mesma. Se nos restantes setores da economia nada acontecer que eleve a produtividade e portanto o poder aquisitivo real, ó mercado para a produção adicional de calçados possivelmente se revelará insuficiente" (Nurkse, 1951:20).

O poder atribuído por Nurkse às "ondas de investimento" para romper o "ciclo vicioso da estagnação" está relacionado com a visão de que o dinamismo das economias avançadas se deve à ação inovadora do empresário (concebido nos moldes do empresário schumpeteriano) e aos agentes imitadores, que propagam os novos produtos e as "novas combinações de fatores". Da ação conjunta e simultânea do "empresário schumpeteriano" e dos seus imitadores resultariam as chamadas "ondas de investimento" que se estendem para os vários setores e ramos da indústria. Estas "ondas de investimento", concentradas no tempo, elevam a produtividade e a renda real e são a "essência e a substância do progresso econômico ao longo prazo - contanto que a composição do aumento da produção consumível corresponda, mais ou menos, à estrutura da procura dos consumidores" (Nurkse, 1951: 20). Como as economias subdesenvolvidas possuem uma deficiência de demanda real, o que se deve à "baixa produtividade que, por sua vez, é largamente devida à falta de capital real" (Nurkse, 1951: 23), o autor recomenda que, para romper com o "estado estacionado", cabe ao Estado não só a organização e a coordenação das forças coletivas, mas também atuar como investidor pioneiro, pois "em um país subdesenvolvido, são precisos os olhos da fé para ver o mercado potencial" (Nurkse, 1951:22).

Ao abordar o problema da escassez de poupança para a formação de capital, Nurkse afirmou que "a pequena taxa de poupança é devida não só ao baixo nível absoluto de renda, mas também à alta propensão a consumir causada pela atração de padrões superiores de consumo" (Nurkse, 1951: 60-1). Na sua visão, a difusão dos padrões de consumo superiores, bem como o conhecimento e o contato com as disparidades 
internacionais de renda e de consumo, seriam altamente estimulados pelos meios de comunicação e pelas estratégias de publicidade. Nas economias desenvolvidas, estes padrões de consumo resultaram de um aumento gradual dos níveis de produtividade, propiciados pela acumulação de capital e pelo progresso técnico, e não seriam compatíveis com os baixos níveis de produtividade, de acumulação de capital e de avanço técnico, observados nas economias subdesenvolvidas. O resultado da assimilação dos padrões de consumo das economias desenvolvidas é o aumento da propensão a consumir, em detrimento da poupança necessária para a formação de capital, cuja intensidade é influenciada pelas disparidades internacionais de produtividade e renda. De acordo com Nurkse:

"É muito mais fácil adotar hábitos superiores de consumo do que melhores métodos de produção. A moda no consumo espalha-se mais rapidamente do que as técnicas de produção. É verdade que os métodos americanos de produção também são largamente imitados; algumas vezes, realmente, em demasia: o equipamento altamente automático que é adequado às condições dos Estados Unidos, onde a mão-de-obra é o fator mais escasso da produção, pode não ser o que melhor se adapte às condições de outros países. Mas, a imitação de métodos americanos de produção requer fundos que possam ser investidos. A tentação para imitar os padrões americanos de consumo tende a limitar a oferta desses fundos de investimento" (Nurkse, $1951: 53-4)$.

Por isto, Nurkse argumentou que, para a explicação da escassez de poupança nas economias subdesenvolvidas, o fenômeno mais importante é a elevada propensão a consumir, e não os baixos níveis de produtividade e de renda, associados aos métodos rudimentares da economia de subsistência. Afirmou ainda que o aumento da renda em termos absolutos não significa necessariamente aumento da capacidade de poupança, se as disparidades internacionais de produtividade e renda não forem reduzidas, para que se diminua a intensidade do "efeito demonstração" sobre a propensão a consumir e, por conseqüência, sobre a capacidade de poupança das economias atrasadas?. Neste ponto, Nurkse ressaltou a sua discordância de Prebisch:

Uma análise do impacto do "efeito demonstração" nas relações entre economias 
O Professor Prebisch acentuou que o nível de produtividade na América Latina é baixo por causa da falta de capital, e o capital é escasso por causa da pequena margem de poupança, à qual é devida à baixa renda e à baixa produtividade. Reconhece também a importância da influência exercida sôbre os países mais pobres pelos padrões de consumo dos mais adiantados. Este segundo ponto, todavia modifica substancialmente o primeiro. A pequena taxa de poupança é devida não só ao baixo nível absoluto de renda, mas também à alta propensão a consumir, causada pela atração de padrões superiores de consumo. [...]

Mesmo nos países mais pobres, o nível absoluto de renda tem aumentado. Mas isso não tornou mais fácil a poupança. Pelo contrário, economizar tornouse mais difícil, porque, a despeito do aumento absoluto, houve um declínio em seus níveis relativos de renda em comparação com os dos principais países. Tem havido um aumento da tensão, da impaciência $e$ da inquietação que causam um deslocamento ascensional dafunção de consumo, a qual age como um impedimento à poupança (Nurkse, 1951: 61, grifos no original).

Porém, um ponto de afinidade entre as abordagens de Prebisch e de Nurkse merece menção, por se referir ao objeto deste trabalho: ambos os autores deram mais ênfase à necessidade do planejamento e do investimento públicos do que à adaptação da tecnologia nas suas respectivas argumentações; o primeiro, porque, dadas as características do progresso técnico, a inadequação de densidade e de escala impediria que se atingisse a densidade ótima de capital; enquanto da análise do segundo se depreende que os problemas relacionados com a inadequação de escala das técnicas assimiladas desestimulavam a acumulação, a absorção da economia de subsistência e a própria ampliação do mercado interno. É interessante notar ainda que a abordagem, conduzida em termos agregados (macro) de ambos os autores, atribuiu pouca relevância à análise dos processos de adaptação tecnológica e ao seu impacto no desenvolvimento das economias periféricas, o que também caracterizou a reflexão de Furtado a respeito do subdesenvolvimento e da sua superação, não obstante a importância atribuída por este autor ao problema do "desequilíbrio ao nível dos fatores" e à adaptação da tecnologia".

desenvolvidas e subdesenvolvidas, particularmente sobre a propensão a consumir e a formação de capital nestas últimas,encontra-se em Nurkse (1951).Sobre o conceito de "efeito demonstração" propriamente, ver Duesenberry. Income, Saving and Theory of Consumer Behavior, Harvard University Press, 1949.

"Sobre a carência de estudos dos processos de adaptação tecnológica e a necessidade 


\section{O "círculo vicioso da estagnação" e a adaptação da tecnologia na visão de Celso Furtado"}

O "desequilíbrio ao nível dosfatores" e a defesa da adaptação da tecnologia

É bem conhecida concepção de Furtado de que o subdesenvolvimento é um fenômeno histórico específico, fruto da expansão das economias industriais, que deu origem a estruturas econômicas heterogêneas, isto é, marcadas pelas disparidades de produtividade e renda entre o setor moderno, dinamizado pela demanda externa de produtos primários, e o setor arcaico, baseado na produção de subsistência, de baixa produtividade e de técnica rudimentar. A falta de sintonia entre a disponibilidade de fatores e as técnicas assimiladas nestas economias é explicada pelo fato de que "o subdesenvolvimento não resulta de transformações endógenas de uma economia pré-capitalista, mas de um processo de enxêrto, nesta última, de uma ou mais emprêsas ligadas ao comércio das economias industrializadas em expansão" (Furtado, 1965: 188). Por isto, Furtado afirmou que o "desequilíbrio ao nível dos fatores" é o filão teórico fundamental para a compreensão do subdesenvolvimento, cuja formulação original se encontra nos textos inaugurais de Prebisch para a CEPAL:

"Ademais de sua importância como contribuição ao estudo da dinâmica do comércio internacional, coube ao estudo de Prebisch papel pioneiro na abertura do debate sobre o que se chamaria depois a peculiaridade do subdesenvolvimento. O processo de propagação da técnica moderna, observava, não se dava nas mesmas condições

de elaboração teórica a respeito da mudança tecnológica nas economias subdesenvolvidas, particularmente focada nos processos de adaptação de tecnologia, ver Katz y Cibotti (1978).

O artigo "Formação de capital e desenvolvimento econômico" (1952) e a obra Desenvolvimento e Subdesenvolvimento (1961) são as duas principais referências das análises de Furtado nos anos 50, utilizadas nesta seção.Vale mencionar que este livro reúne artigos e ensaios originalmente escritos ao longo dos anos 50 e 60 , publicados em diversos periódicos como El Trimestre Económico e Econômica Brasileira. No artigo citado, incluído com algumas modificações no livro de 1961, Furtado teceu comentários sobre as conferências de Ragnar Nurkse no Brasil no ano de 1951 e foi publicado na Revista Brasileira de Economia, v. 6, n. 3, 1952. As considerações de Nurkse sobre este artigo de Furtado foram publicadas no mesmo periódico, v. 7, n. 1, 1953, com o título "Formação de capitais e desenvolvimento econômico". 
nos países centrais e nos periféricos."Quando os que hoje são grandes centros industriais, observava, estavam em condições comparáveis às que agora apresentam os países periféricos (...) a técnica moderna exigia um capital por homem relativamente exíguo". E concluía: quanto mais tarde chega a um país a técnica moderna, tanto maior o contraste entre o baixo nível de sua renda per capita e a magnitude do capital necessário para aumentar essa renda. Aí tem origem toda uma problemática nova. Ademais, como ignorar que a técnica moderna tem exigências em matéria de dimensão de mercado, que raramente são satisfeitas por um país periférico? Por outro lado, o progresso técnico nas formas de consumo engendra na periferia uma forte propensão a consumir objetos sofisticados, quase sempre importados, criando um desequilíbrio adicional entre poupança disponível e exigências de capitalização. E ainda debateu o problema da combinação ótima defatores nos países periféricos, ou de desequilíbrio ao nível de fatores engendrado pela penetração da técnica moderna, que conduziu ao conceito de produtividade social" (Furtado, 1985:79-80, grifos nossos) ${ }^{10}$.

Para Furtado, na industrialização substitutiva de importações, a tecnologia é uma variável independente e não adequada às disponibilidades de recursos e fatores, seja por estar incorporada aos equipamentos importados, seja porque a industrialização substitutiva conduziu à assimilação de "tecnologia compatível com uma estrutura de custos e preços similar à que prevalece no mercado internacional" (Furtado, 1965:188). O argumento completo é o seguinte:

"O núcleo industrial ligado ao mercado interno se desenvolve através de um processo de substituição de manufaturas antes importadas, vale dizer em condições de permanente concorrência com produtores forâneos. Daí resulta que a maior preocupação do industrial local é a de apresentar um artigo similar ao importado e adotar métodos de produção que o habilitem a competir com o exportador estrangeiro. Por outras palavras, a estrutura de preços, no setor industrial ligado ao mercado interno, tende a assemelhar-se à que prevalece nos países de elevado grau de industrialização, exportadores de manufaturas. Assim sendo, as inovações tecnológicas que

Furtado refere-se nesta citação ao Estudo de Í949, apresentado na conferência de Montevidéu, em maio de 1950. 
se afiguram mais vantajosas são aquelas que permitem aproximar-se da estrutura de custos e preços dos países exportadores de manufaturas, e não as que permitam uma transformação mais rápida da estrutura econômica, pela absorção do setor de subsistência. O resultado prático disso - mesmo que cresça o setor industrial ligado ao mercado interno e aumente sua participação no produto, mesmo que cresça, também, a renda per capita do conjunto da população - é que a estrutura ocupacional do país se modifica com lentidão. O contingente da população afetada pelo desenvolvimento mantém-se reduzido, declinando muito devagar a importância relativa do setor cuja principal atividade é a produção para subsistência. Explica-se, dêste modo, que uma economia, onde a produção industrialjá alcançou elevado grau de diversificação e tem uma participação no produto que pouco se distingue da observada em países desenvolvidos, apresente uma estrutura ocupacional tipicamente pré-capitalista e que grande parte de sua população esteja alheia aos benefícios do desenvolvimento" (Furtado, 1965:185).

De acordo com o autor, a assimilação de tecnologias de alta densidade de capital e elevada escala de produção dificultaria a absorção do setor de subsistência, a diminuir o emprego por unidade de investimento. Além disto, estas tecnologias teriam o efeito de desarticular a produção de subsistência preexistente, gerando desemprego tecnológico. A conseqüência é que as tecnologias "poupadoras de trabalho" não aumentariam a produtividade do trabalho para o conjunto do sistema econômico e limitariam a absorção do setor de subsistência, dificultando a ampliação do mercado interno na dimensão compatível com a escala de produção das técnicas modernas. A capacidade ociosa excessiva tenderia a reduzir a produtividade do capital, elevando o custo do investimento que incorpora as tecnologias avançadas. Neste sentido, na perspectiva de Furtado, a inadequação de densidade apenas reforça as limitações associadas à inadequação de escala das tecnologias assimiladas nas economias subdesenvolvidas:

"O que se busca com o desenvolvimento econômico é aumentar a produtividade física média do fator trabalho. Numa economia subdesenvolvida a introdução de máquinas automáticas de fabricar sapatos não significa melhora na produtividade física do fator trabalho para o conjunto da coletividade se os artesãos que antes produziam sapatos ficaram sem nenhuma ocupação. Por outro lado, o empresário 
que introduza tais máquinas terá prejuízo porque elas terão de permanecer paradas 5 dias por semana. Mas o empresário que introduza melhoras nas ferramentas utilizadas na produção manual de sapatos e assim possibilite um aumento de produtividade, produzirá mais sapatos com o mesmo número de homens-hora sem elevar demasiadamente outros custos" (Furtado, 1952: 11).

O desajustamento entre a tecnologia e a disponibilidade de fatores nas economias subdesenvolvidas impede o pleno emprego simultâneo de capital e trabalho ou, conforme afirmou Furtado,"a plena utilização do capital disponível não é condição suficiente para a completa absorção da fôrça de trabalho, ao nível de produtividade correspondente à tecnologia que prevalece no setor dinâmico do sistema" (Furtado, 1965: 187). Por outro lado, a combinação ótima dos fatores nestas economias - onde há escassez de capital e abundância de mão-de-obra-seria dificultada pela relativa rigidez dos coeficientes técnicos que "é particularmente grande no setor que desempenha o papel mais dinâmico no crescimento, que é o industrial" (Furtado, 1965:88). Com este argumento, Furtado parece incorporar a proposição de Prebisch de que, na agricultura, há maior flexibilidade de combinação dos fatores, devido à maior disponibilidade de técnicas "poupadoras de capital" e "poupadoras de trabalho", e que às técnicas industriais correspondem proporções bem definidas de fatores. De acordo com o autor:

"Dentro dos padrões da técnica conhecida, numa região subdesenvolvida sempre existe deficiente utilização dos fatôres de produção. Essa deficiência, sem embargo, não resulta necessàriamente de má combinação dos fatores existentes. O mais comum é que resulte da escassez do fator capital. Desperdiça-se um fator - mão-de-obra porque outro é insuficiente - capital. Dessa forma, a produtividade média de um conjunto de fatôres em uma economia subdesenvolvida é menor do que seria de esperar se observamos a utilização dêsses fatôres nas economias desenvolvidas. Deve-se isso à relativa fixidez dos coeficientes técnicos (não é possível combinar fatôres senão em determinadas proporções) e ao fato de que a tecnologia vem se desenvolvendo em função da disponibilidade de fatores e recursos dos países que lideram o processo de industrialização" (Furtado, 1965: $88)$.

Diante da impossibilidade de alcançar a combinação ótima de fatores 
e elevar simultaneamente a produção e o emprego na periferia (devido à inadequação de densidade), os países subdesenvolvidos não se poderiam limitar a assimilar as técnicas intensivas em capital. Na perspectiva de Furtado, o desequilíbrio entre a oferta de fatores e a orientação tecnológica somente poderia ser contornado mediante a adaptação da tecnologia - a adoção de técnicas de menor densidade de capital, a criação tecnológica adequada à disponibilidade de fatores - e a implantação do setor de bens de capital nas economias subdesenvolvidas. A adaptação da tecnologia e a incorporação do setor de bens de capital são encaradas como instrumentos para lidar com tais desajustes:

"Se é verdade que os países subdesenvolvidos crescem pela simples assimilação de técnicas já conhecidas (e pela correspondente acumulação de capital), também o é que a transplantação dessas técnicas traz implícito, quase sempre, um subemprego estrutural de fatores. Essa dificuldade não poderá ser contornada senão através de um esforço de adaptação da tecnologia, o qual é tanto mais difícil quanto os países subdesenvolvidos carecem, via de regra, de indústria própria de equipamentos. Nesse desajustamento básico entre oferta virtual de fatores e orientação da tecnologia reside, possivelmente, o maior problema que enfrentam atualmente os países subdesenvolvidos" (Furtado, 1965: 89).

Assim, nas análises realizadas ao longo dos anos 50, são predominantes as idéias de que o problema fundamental do subdesenvolvimento é o "desequilíbrio ao nível dos fatores" e que o esforço de adaptação da tecnologia requer a implantação do setor de bens de capital. A defesa da adaptação tecnológica baseou-se no argumento de que, mesmo que a acumulação e a incorporação de tecnologias intensivas em capital elevem o nível de produtividade e de renda no setor desenvolvido, se ela não promover a absorção da mão-de-obra do setor arcaico e todo o aumento da população permanecer ocupado a nível de produtividade deste setor, "o aumento resultante da renda per capita do conjunto da população não se faz acompanhar, necessàriamente, de aumento relativo do setor desenvolvido" (Furtado, 1965: 189). A adaptação da tecnologia foi encarada como requisito crucial no esforço de mudança significativa na estrutura ocupacional e na diminuição da importância relativa do setor de subsistência, sem o que, de acordo com Furtado, não se alteraria o grau de subdesenvolvimento. 
A escassez de poupança e o "círculo vicioso da estagnação"

No artigo "Formação de capital e desenvolvimento econômico" (1952), Furtado se propôs a analisar o problema da escassez de poupança nas economias subdesenvolvidas numa perspectiva histórica. O autor sustentou a idéia de que o principal obstáculo à acumulação, nas economias pré-industriais, foi os baixos níveis de produtividade e não a pequena dimensão do mercado interno. As economias subdesenvolvidas e as pré-industriais teriam em comum a incapacidade de iniciar um processo de desenvolvimento sustentado pela expansão do mercado interno, devido à baixa produtividade e ao reduzido excedente disponível para diversificação do consumo e/ou inversão. Argumentou ainda que foi a expansão do mercado externo e não a do interno que rompeu com a estagnação característica das economias pré-industriais, o que também se aplicaria às economias subdesenvolvidas ${ }^{11}$. Pelas palavras do autor:

"As grandes dificuldades do desenvolvimento se encontram, portanto, nos níveis mais baixos de produtividade. Iniciado o processo de crescimento, a dinâmica própria dêste faz com que parte do aumento da renda se reserve para a capitalização. Uma comunidade primitiva, todavia, tende a ficar estagnada, pois com seus próprios meios dificilmente pode darinício a um processo de desenvolvimento. O impulso inicial que permite superar essas dificuldades veio, històricamente, de fora da comunidade.

O estabelecimento de uma corrente de intercâmbio externo cria, em uma economia de baixos níveis de produtividade, a possibilidade de iniciar um processo de desenvolvimento sem prévia acumulação de capital" (Furtado, 1965: 91).

Furtado atribuiu os aumentos de produtividade propiciados pelo comércio à utilização mais eficiente dos recursos disponíveis, à especialização e ao aprofundamento da divisão do trabalho. Na sua interpretação, foi a diversificação da procura, trazida pelo desenvolvimento do comércio, o elemento dinâmico exógeno a permitir aumentos de produtividade sem acumulação prévia, pois a expansão do comércio externo

"Este argumento, baseado na análise do processo histórico de desenvolvimento, aproxima as abordagens de Furtado e de Prebisch sobre a escassez de poupança, em contraste com a abordagem de Nurkse, que atribuiu a estagnação das economias subdesenvolvidas principalmente à pequena dimensão do mercado interno. 
criou uma margem ou excedente que viabilizou o desenvolvimento econômico. Conforme ressaltou o autor,

\begin{abstract}
"(...) é possível introduzir combinações mais produtivas sem prévio aumento da disponibilidade de capital, ou pelo menos sem prévio aumento da oferta de capital em sua forma complexa de equipamentos. É o que ocorre com a abertura de uma linha de comércio exterior, por iniciativa externa. Surge, então, a possibilidade de utilização mais a fundo e, possivelmente, em combinações mais racionais, de fatôres disponíveis em abundância: terra e mão-de-obra.É o caso clássico a que se referia Adam Smith quando afirmava que a divisão do trabalho estava limitada pelas dimensões do mercado. O aumento da renda real, assim obtido, poderá constituir a margem necessária em que se apoiará a economia para darinício ao processo de acumulação de capital. Essa simples indicação põe em evidência a grande importância que tem para os países subdesenvolvidos a expansão do comércio mundial" (Furtado, 1965: 92, grifos nossos).
\end{abstract}

Para Furtado, o conceito de "círculo vicioso da estagnação", formulado com base na relação entre o incentivo a investir e a pequena dimensão do mercado diante da escala de produção das técnicas modernas, não se aplicaria às economias subdesenvolvidas mais complexas, como a economia brasileira. Enquanto Nurkse propôs a ampliação do mercado interno, através do investimento público, para romper com a estagnação, Furtado afirmou que ela foi rompida historicamente através da expansão do mercado externo - da expansão comercial que permitiu aumentos de produtividade sem prévia acumulação. Ainda que considere a existência de vários pontos comuns com as idéias de Ragnar Nurkse, o autor comenta na Fantasia Organizada (1985):

"Nurkse, parecia-me, raciocinava como se os países subdesenvolvidos estivessem estagnados, presos na armadilha do 'círculo vicioso da miséria'. Essa situação poderia existir em algumas partes do mundo, mas não era a que nos preocupava. Os atuais países subdesenvolvidos, dizia eu, foram atraídos, num processo histórico, para o sistema de divisão internacional do trabalho, recebendo dessa forma um impulso que os retirou da estagnação. Fazia essas observações como simples excusa para apresentar um corpo ordenado de idéias, em grande parte as mesmas que utilizara Nurkse, mas apresentadas de outra forma" (Furtado, 1985:149-50). 
Furtado argumentou que a inserção das economias subdesenvolvidas na divisão internacional do trabalho gerou ganhos de produtividade que permitiram romper com a estagnação. No caso brasileiro, o setor exportador ligado ao mercado internacional foi absorvendo a economia de subsistência o "suficiente para dar caráter monetário a uma importante faixa do sistema econômico" (Furtado, 1965: 178). O maior emprego no setor exportador incorporou à economia de trocas a mão-de-obra subocupada no setor de subsistência, com o conseqüente aumento da importância relativa da renda monetária no sistema econômico. Por sua vez, o aumento da renda monetária provocou a ampliação e a diversificação do consumo, atendidas inicialmente por meio de importações, mas, segundo o autor, estimulou também as atividades ligadas ao mercado interno ${ }^{12}$.

As fases de crise do setor exportador - marcadas por contração da demanda externa de produtos primários, redução dos preços de exportação e desvalorização cambial - estimulavam o setor ligado ao mercado interno. Já nas etapas de expansão do setor exportador, a melhora da capacidade de importar teria o efeito de reduzir o multiplicador interno da renda, devido ao aumento da concorrência dos produtos importados. Deste modo, o crescimento do núcleo industrial tendeu a se acentuar nas fases de declínio da rentabilidade do setor exportador, quando a diminuição da capacidade de importar e a desvalorização cambial atuavam no sentido de estimular a produção interna de manufaturados. Nestas fases, de acordo com Furtado, a rentabilidade e a expansão do setor industrial eram estimuladas pela demanda de bens de consumo e de capital, não obstante o aumento do preço de reposição dos equipamentos importados, que acompanhava a redução da capacidade de importar.

Em síntese, a argumentação central de Furtado é que a progressiva absorção do setor de subsistência pelo setor exportador e a instabilidade da capacidade de importar, combinada com a estabilidade da renda monetária, criaram um mercado interno de produtos manufaturados, quejustificou o desenvolvimento de um núcleo industrial - inicialmente a indústria leve de bens de consumo em geral - voltado para o mercado interno. Em trabalhos do final dos anos 50 (refletindo talvez uma preocupação com os resultados do desenvolvimento industrial brasileiro), Furtado afirmou que o resultado deste processo foi a formação de uma

Uma recuperação das idéias de Furtado sobre as origens da indústria no Brasil encontra-se em Szmrecsányi (2002). 
estrutura subdesenvolvida complexa, constituída por "três setores: um, principalmente de subsistência; outro, voltado sobretudo para a exportação, e o terceiro, como um núcleo industrial ligado ao mercado interno, suficientemente diversificado para produzir parte dos bens de capital de que necessita para seu próprio crescimento" (Furtado, 1965: 184). Porém, u ma característica da industrialização por substituição de importações é que "o elemento dinâmico reside ainda na procura preexistente - formada, principalmente, por indução externa - e não nas inovações introduzidas nos processos produtivos, como ocorre nas economias industriais totalmente desenvolvidas"13 (Furtado, 1965: 183).

\section{Raúl Prebisch, Ragnar Nurkse e Celso Furtado: algumas considerações finais}

A concepção de progresso técnico da economia clássica, presente nas formulações iniciais de Prebisch para a CEPAL, foi compartilhada por Furtado, que incorporou também a concepção do desenvolvimento associado à homogeneização da estrutura econômica e buscou sustentála a partir da sua interpretação do processo histórico de acumulação. Com uma argumentação baseada em elementos históricos do desenvolvimento capitalista, Furtado reafirmou idéias - comuns a Prebisch — de que a difusão de técnicas acompanha o processo de homogeneização da estrutura econômica, de que o progresso técnico não é necessariamente causador de desemprego, elevando a produtividade do trabalho à medida que se difunde para o conjunto do sistema econômico, o que permitiu o aumento do salário real, estimulado pela pressão da acumulação sobre o mercado de trabalho ${ }^{14}$.

Furtado considera o progresso técnico como uma dimensão da acu-

Furtado aprimorou conceitualmente estas idéias em obras posteriores ao período que interessa abordar neste trabalho. Um estudo da evolução das idéias do autor a respeito da relação entre progresso técnico, industrialização e subdesenvolvimento encontra-se em D'Arbo (2001).

14 Em Furtado (1954), Furtado (1955) e Furtado (1965) é possível observar a construção do seu "modelo clássico de desenvolvimento industrial". Especificamente em Furtado (1965), o autor se referiu à abordagem da economia clássica do progresso técnico como um meio de substituição de trabalho por capital, em função da disponibilidade e do preço relativo destes fatores de produção, atribuindo-a principalmente a David Ricardo. Outra característica da abordagem da economia clássica é a associação do progresso técnico com a acumulação e o desenvolvimento do setor de bens de capital, tomando-o como fator primordial do crescimento de longo prazo. 
mulação ao mesmo tempo em que a viabiliza, pois a continuidade do processo de acumulação dependeria do dinamismo tecnológico, ou seja, o desenvolvimento não se poderia basear apenas na difusão de técnicas, na ampliação das economias de escala e das economias externas, já que a produtividade do trabalho tende a diminuir para os investimentos de uma mesma geração tecnológica. Além disto, o progresso técnico não se manifesta apenas como novos processos produtivos, mas ta mbém como inovações de produtos.

Foi mencionado que Nurkse atribuiu o dinamismo da economia capitalista ao empresário inovador (nos moldes schumpeterianos) e aos seus imitadores, cujo papel é o de difundir os novos produtos e processos produtivos. Furtado compartilhou da idéia do desenvolvimento associado às inovações e/ou difusão de produtos e processos, mas fez a qualificação de que o "empresário industrial" surgiu historicamente na transição da economia comercial para a economia industrial européia, não concordando com o que chamou de concepção abstrata do "empresário schumpeteriano", adotada por Nurkse ${ }^{15}$.

É comum às abordagens de Prebisch e de Nurkse, em primeiro lugar, a idéia de que as inovações tecnológicas estão disponíveis para serem assimiladas pelas economias subdesenvolvidas, não existindo maiores entraves para a sua aquisição; em segundo lugar, a concepção de que a pequena dimensão do mercado, em relação à escala de produção, desestimula a acumulação de capital e a absorção da economia de subsistência; em terceiro lugar, que a elevada propensão a consumir tende a reduzir a capacidade de poupança das economias periféricas.

Porém Nurkse enfatizou os problemas relacionados com a inadequação de escala como o principal obstáculo à acumulação, à eliminação da heterogeneidade estrutural e à ampliação do mercado interno. Este autor recomendou o investimento público para gerar economias externas, a fim de estimular a acumulação, os aumentos de produtividade e, conseqüentemente, a absorção do setor de subsistência e o aumento da dimensão real do mercado. Em que pese a assimilação de tecnologias de elevada densidade de capital e escala de produção, Nurkse deu maior ênfase à necessidade de ampliação do mercado e não à adaptação da tecnologia - é a dimensão do mercado que deveria ser "adaptada" e não a tecnologia. Outra idéia que mereceu o destaque de Nurkse foi a

Considerações críticas de Furtado sobre a concepção do empresário de Schumpeter podem ser encontradas nos seguintes trabalhos: Furtado (1952), Furtado (1954) e Furtado (1965). 
de que a insuficiência de poupança decorria principalmente da elevada propensão a consumir, intensificada pelas disparidades de renda e padrões de consumo entre economias desenvolvidas e subdesenvolvidas, o que impedia a canalização dos aumentos de produtividade para a acumulação.

Em contraste, Prebisch procurou diferenciar o impacto da inadequação de densidade de capital e de escala de produção na dinâmica da acumulação, na geração de emprego e na absorção do setor arcaico das economias periféricas. Para ele, a absorção da economia de subsistência foi dificultada não só pela inadequação de escala, que desestimulava a acumulação no setor moderno, mas também pelo desemprego tecnológico, provocado pela inadequação de densidade das tecnologias avançadas. Por outro lado, em que pese o fenômeno da elevada propensão a consumir, a escassez de poupança resultaria principalmente da baixa produtividade das economias heterogêneas, o que tendeu a se intensificar com as disparidades internacionais de nível da técnica, de produtividade e de renda. Os baixos níveis de produtividade tornaram a poupança escassa diante da necessidade de capital das tecnologias de elevada densidade.

De acordo com o exposto anteriormente, a principal recomendação de Prebisch, foi a minimização dos problemas de escala e do desemprego tecnológico através da "distribuição adequada dos investimentos realizados no setor moderno entre atividades competitivas e não-competitivas" (Rodríguez, 1981: 87) com o setor arcaico, para que a acumulação absorvesse a economia de subsistência, reduzindo a heterogeneidade estrutural das economias periféricas. Contudo, de acordo com Furtado, a recomendação de Prebisch incluiria a modificação na densidade de capital, isto é, a adaptação tecnológica à disponibilidade de fatores da periferia. Comentando os Problemas Teóricos e Práticos do Desenvolvimento (1973), Furtado escreveu, na Fantasia Organizada (1985):

"Tampouco se podia desconhecer que a disponibilidade de fatores, no país periférico, não correspondia à tecnologia disponível, toda ela oriunda de países em que a dotação de capital por pessoa empregada era substancialmente mais elevada."O escasso capital disponível, dizia-se, deveria ser empregado de forma a conseguir o aumento máximo de produção, economizando mão-de-obra somente à medida que o capital disponível permita absorvê-la noutras atividades". Daí a necessidade de "adaptar a técnica moderna a esses países evitando limitar-se a transfundi-la". Esta parte do estudo não está adequadamente elaborada, mas apontava na mesma direção da anterior, refor- 
çando a tese de necessidade de programação do desenvolvimento, se se pretendia intensificar o seu ritmo e/ou reduzir o seu custo social" (Furtado, 1985: 97).

Na perspectiva de Furtado, Prebisch iniciou o debate sobre o problema da combinação ótima dos fatores na periferia, mas limitou-se a utilizá-lo como argumento para a defesa da programação do desenvolvimento, e não para defender a necessidade de se alterar a densidade de capital das inovações tecnológicas. E concluiu sobre a importância das idéias de Prebisch para a sua própria percepção da relação teórica entre subdesenvolvimento e progresso técnico, mais precisamente da necessidade de explorar teoricamente a relação entre o "desequilíbrio ao nível dos fatores" e a criação de técnicas de menor densidade de capital, isto é, a adaptação tecnológica:

"Estes debates foram de importância decisiva para mim, pois me permitiram perceber que o subdesenvolvimento configurava um quadro histórico qualitativamente distinto daquele que tínhamos no espírito quando teorizávamos sobre o desenvolvimento. Não se tratava de uma fase e sim de algo diferente, cuja especificidade cumpria captar. Havíamos concentrado a atenção na acumulação e no progresso técnico. Ora, se era possível isolar a categoria acumulação de seu contexto histórico, definindo-a como uma relação entre produção total e produção consumida, já não acontecia o mesmo com o progresso técnico, que emergia em certo contexto sócio-econômico do qual derivava o seu sentido.

Se pode ser racional preservar equipamentos obsoletos ou forçar a sua utilização é porque a nova tecnologia é disfuncional com respeito à oferta de fatores de produção. Prebisch fizera referência a esse problema no Estudo de 1949 , mas absteve-se de levar o raciocínio a suas últimas conseqüências. No novo estudo ele o utilizará como argumento para fundar a necessidade de programar o desenvolvimento. A mim me pareceu que havíamos descoberto uma fresta pela qual podíamos olhar a fundo na problemática do subdesenvolvimento, cujo campo de teorização ganha autonomia" (Furtado, 1985: 88-9, grifos nossos).

Por fim, vale mencionar que, nos anos 50, as análises de Furtado apontaram para a necessidade de adaptação da tecnologia e da internalização da produção de bens de capital, o que estava em sintonia com a tese dominante na CEPAL sobre a capacidade da industrialização de 
promover a superação do subdesenvolvimento. No que se refere à adaptação da tecnologia ou, mais precisamente, à necessidade de criação tecnológica adequada à dotação de fatores nas economias subdesenvolvidas, um aspecto que merece ser destacado é que, no argumento de Prebisch, predominou a consideração de que as tecnologias de elevada densidade de capital são pouco adaptáveis e que as técnicas de menor densidade de capital são menos eficientes, reduzindo o nível da renda, embora pudessem favorecer o emprego. Em contraste, a importancia atribuída por Furtado às técnicas de menor densidade de capital se deveu ao fato de que elas elevariam a produtividade do trabalho sem reduzir significativamente a absorção de mão-de-obra, além do que, na concepção do autor, dada a heterogeneidade tecnológica, "em muitas regiões do Brasil a mera introdução da roda significaria um sensível progresso" (Furtado, 1952: 11).

\section{Referências bibliográficas}

D'Arbo, Renata. Progresso técnico no pensamento de Celso Furtado. Araraquara, 2001,172 pp. Dissertação (Mestrado) - Faculdade de Ciências e Letras, Universidade Estadual Paulista.

Furtado, Celso. Formação de capital e desenvolvimento econômico. Revista Brasileira de Economia. V. 6, n. 3, set. 1952: 7-46.

A economia brasileira: contribuição à análise do seu desenvolvimento. Rio de Janeiro: A Noite, 1954.

. O desenvolvimento econômico - ensaio de interpretação histórico-analítica.

Econômica Brasileira. V. 1,n. 1,jan.-mar. 1955:3-24.

Desenvolvimento e subdesenvolvimento. Rio de Janeiro: Fundo de Cultura, 1965.

A fantasia organizada. Rio de Janeiro: Paz e Terra, 1985.

Katz, Jorge, Cibotti, Ricardo. Marco de referencia para un programa de investigación en temas de ciencia y tecnologia en la América Latina. El Trimestre Económico. V. 45, n. 177, ene.-mar. 1978: 139-65.

Nurkse, Ragnar. A formação de capital em países subdesenvolvidos. Revista Brasileira de Economia. V. 5, n. 4, dez. 1951:11-190.

Prebisch, Raúl. Interpretação do processo de desenvolvimento econômico. Revista Brasileira de Economia. V. 5, n. 1, mar. 1951: 7-135.

Problemas teóricos y prácticos del crecimiento económico. Santiago de Chile: CEPAL, 1973.

Rodríguez, Octávio. Teoria do subdesenvolvimento da CEPAL. Rio de Janeiro: Forense Universitária, 1981.

Szmrecsányi, Tamás. Celso Furtado e o início da industrialização no Brasil. Revista de Economia Politica. V. 22, n. 2, abr.-jun. 2002: 3-14. 